Research, Society and Development, v. 9, n. 10, e2839108602, 2020

(CC BY 4.0) | ISSN 2525-3409 | DOI: http://dx.doi.org/10.33448/rsd-v9i10.8602

\title{
Retinopatia em pacientes com doença falciforme: uma revisão de literatura
}

Retinopathy in patients with falciform disease: a literature review

Retinopatía en pacientes con falciformas: revisión de la literatura

Recebido: 18/09/2020 | Revisado: 21/09/2020 | Aceito: 24/09/2020 | Publicado: 26/09/2020

Arthur Freitas do Nascimento

ORCID: https://orcid.org/0000-0002-7911-0119

Faculdade Irecê, Brasil

E-mail: arthurf.enf@gmai.com

Lorrana Figueirêdo Pereira

ORCID: https://orcid.org/0000-0002-4235-2798

Faculdade Irecê, Brasil

E-mail: lorranaf.pereira@ @otmail.com

Márcio Cerqueira de Almeida

ORCID: https://orcid.org/0000-0002-2903-7283

Faculdade Irecê, Brasil

E-mail: marcioalameidaprofessor@gmail.com

José Eduardo Teles de Andrade

ORCID: https://orcid.org/0000-0001-8602-8079

Faculdade Irecê - FAI, Brasil

E-mail: telesandrade31@ hotmail.com

Claudilson Souza Dos Santos

ORCID: https://orcid.org/0000-0002-9412-8480

Faculdade Irecê, Brasil

E-mail: claudilsonsouza@hotmail.com

Morganna Thinesca Almeida Silva

ORCID: https://orcid.org/0000-0002-8508-1051

Faculdade Irecê, Brasil

E-mail: morgannafarma@hotmail.com

Edilson da Silva Pereira Filho

ORCID: https://orcid.org/0000-0002-8632-5337

Faculdade Irecê, Brasil

E-mail: eddi_filho@hotmail.com 


\title{
Resumo
}

Objetivo: Descrever os fatores que desencadeiam a retinopatia na doença falciforme. Método: foi utilizada uma revisão bibliográfica integrativa com abordagem qualitativa, utilizando como fonte de dados as bases digitais da BVS, Scielo, PUBMED e LILACS, respeitando o recorte temporal de 2005 a 2020, onde foram encontrados 40 artigos, os quais foram lidos os seus títulos e resumos, e a partir disso, foram utilizados 13 para os resultados, estes por sua vez, foram organizados em três categorias e depois analisados e discutidos. Resultados: Após leitura e análise dos dados foi possível verificar que há uma incidência acentuada da retinopatia falciforme, a qual afeta entre 10 a 20\% dos falcêmicos nas diferentes faixas etárias e em todos os subtipos da patologia, sendo mais recorrente no grupo SC e logo após o SS, respectivamente, atrelado a isso, foi possível verificar que o principal fator para o surgimento da retinopatia na doença falciforme é a ocorrência dos fenômenos vaso-oclusivos das macro e microcirculações, tais fenômenos acabam comprometendo a oxigenação da retina. Conclusão: Destaca-se que o objetivo e problemas que nortearam este estudo foram contemplados, entretanto, o mesmo apresenta lacunas que podem ser respondidas e exploradas mais a fundo de outro ponto de vista, mas a partir dele, notou-se a falta de estudos atuais no Brasil que abordem sobre a retinopatia falcêmica.

Palavras-chave: Anemia falciforme; Alterações oculares; Retinopatia.

\begin{abstract}
Objective: Describe the factors that trigger retinopathy in sickle cell disease. Method: an integrative bibliographic review with a qualitative approach was used, using the VHL, Scielo, PUBMED, and LILACS digital databases as a data source, respecting the time frame from 2005 to 2020, where 40 articles were found, which were read. titles and abstracts, and from that, 13 were used for the results, these, in turn, were organized into three categories and then analyzed and discussed. Results: After reading and analyzing the data, it was possible to verify that there is a marked incidence of sickle cell retinopathy, which affects between 10 and $20 \%$ of sickle cell patients in different age groups and all pathology subtypes, being more frequent in the SC group and soon after SS, respectively, linked to this, it was possible to verify that the main factor for the emergence of retinopathy in sickle cell disease is the occurrence of vaso-occlusive phenomena of macro and microcirculation, such phenomena end up compromising retinal oxygenation. Conclusion: It is noteworthy that the objective and problems that guided this study were addressed, however, it has gaps that can be answered
\end{abstract}


and explored further from another point of view, but from it, there was a lack of studies current in Brazil that address sickle cell retinopathy.

Keywords: Sickle cell anemia; Eye changes; Retinopathy.

\section{Resumen}

Objetivo: Describir los factores desencadenantes de la retinopatía en la anemia de células falciformes. Método: se utilizó una revisión bibliográfica integradora con enfoque cualitativo, utilizando como fuente de datos las bases de datos digitales BVS, Scielo, PUBMED y LILACS, respetando el marco temporal de 2005 a 2020, donde se encontraron 40 artículos, los cuales fueron leídos. títulos y resúmenes, y de ahí se utilizaron 13 para los resultados, estos a su vez se organizaron en tres categorías y luego se analizaron y discutieron. Resultados: Tras la lectura y análisis de los datos, se pudo constatar que existe una marcada incidencia de retinopatía drepanocítica, que afecta entre un 10 y un $20 \%$ de los pacientes drepanocíticos en diferentes grupos de edad y en todos los subtipos de patología, siendo más frecuente en el grupo SC y próximamente luego del SS, respectivamente, ligado a esto, se pudo verificar que el principal factor para la aparición de retinopatía en la anemia drepanocítica es la ocurrencia de fenómenos vasooclusivos de macro y microcirculaciones, dichos fenómenos terminan comprometiendo la oxigenación retiniana. Conclusión: Cabe mencionar que se abordaron el objetivo y problemas que guiaron este estudio, sin embargo, tiene lagunas que se pueden responder y explorar más a fondo desde otro punto de vista, pero desde el mismo, faltaron estudios. actual en Brasil que abordan la retinopatía drepanocítica.

Palabras clave: Anemia de células falciformes; Cambios en los ojos; Retinopatía.

\section{Introdução}

A Doença Falciforme é considerada um grupo de hemoglobinopatias, de caráter genético e hereditário, onde o organismo possui uma deficiência na produção das hemoglobinas, as quais irão tornar as hemácias rígidas e defeituosas, perdendo a capacidade de armazenar oxigênio, ocasionando uma maior viscosidade no sangue, colaborando diretamente para a oclusão de microcirculações em diferentes graus. Este processo de vasooclusão desencadeia episódios de crises dolorosas nos pacientes, podendo ocasionar lesão em órgãos e sistemas tais como cérebro, coração, fígado, rins, pele, olhos, esqueleto e pulmões (David, Júnior \& Rodrigues, 2011). 
Nessa perspectiva, o Ministério da Saúde (Brasil, 2014), aborda que, a Doença Falciforme é considerada uma "doença de negros", porque tem uma incidência muito elevada nos países da África, Arábia Saudita e Índia. No Brasil, devido à grande miscigenação genética, resultado da escravidão, há uma incidência de 1:1.000 nascidos vivos. Dentre os Estados do país, a Bahia é o que mais sofre com o acometimento da patologia, sendo 1:650 nascidos vivos. Essa alta taxa de incidência é o que a torna uma patologia de agravos relevantes.

A pessoa com Doença Falciforme possui grandes possibilidades de desenvolver diversas complicações, devido a mesma ser fator de risco para o surgimento de diversas outras patologias, por conta das vaso-oclusões sistêmicas nas micro e macro circulações, a exemplo as alterações retinianas, em especial a Retinopatia, onde o paciente pode vir a ter um comprometimento da visão de forma parcial ou até mesmo total, caso não seja descoberta e tratada precocemente (David, Júnior \& Rodrigues, 2011).

Dessa forma, a origem do presente estudo justifica-se devido ao acometimento da retinopatia associada à Anemia Falciforme em um dos autores. O comprometimento da visão de qualquer pessoa pode vir a torná-la incapaz de realizar algumas das atividades básicas diárias da vida. Por esta razão, o estudo vigente tem como pergunta norteadora: Por qual razão os pacientes com doença falciforme são acometidos pela retinopatia? Além disso, possui como objetivo: Descrever os fatores que desencadeiam a retinopatia na Doença Falciforme.

Atrelado a isso, a falta de estudos científicos que abordam sobre o assunto em questão, em especial no cenário brasileiro, tornaram-se peças essenciais para a projeção e realização do referido estudo.

Portanto, como citado acima, este estudo foi construído visando explanar para o meio científico, acadêmico e em especial para a sociedade brasileira, informações a respeito da Doença Falciforme e a forma como ela pode progredir e facilitar o surgimento de outras patologias, a exemplo da retinopatia. Esta, por sua vez, por ser uma complicação insidiosa e silenciosa necessita ser diagnosticada e tratada precocemente. Em virtude disso, é necessário que haja práticas de promoção e diagnóstico. Para isso, é preciso ter informações disponíveis, e este estudo foi criado neste intuito. 


\section{Metodologia}

O presente estudo trata-se de uma revisão bibliográfica integrativa, a qual provém de uma síntese de conhecimentos existentes atualmente sobre a temática em estudo. Desse modo, a revisão bibliográfica integrativa proporciona a identificação, análise e sintetização dos resultados do estudo de maneira independente sobre o assunto em questão (Souza, Silva \& Carvalho, 2010).

Nessa perspectiva, a revisão integrativa possui um protocolo pré-estabelecido que norteia o pesquisador durante todo o processo da construção do trabalho, desde a escolha do problema até o resultado. Portanto, ela se baseia em seis passos, sendo eles: escolha e definição do tema; busca de material na literatura; definição de critérios para análise de dados; avaliação dos estudos incluídos nos resultados; discussão dos resultados encontrados; e por fim, apresentação da revisão (Mendes, Silveira \& Galvão, 2008).

De fato, a abordagem de pesquisa de caráter qualitativa determinada para o presente estudo permite a criação de novas perspectivas acerca do tema escolhido, a partir da utilização de estudos qualitativos resumidos, o que auxilia diretamente na composição de novas teorias. Sendo assim, a pesquisa qualitativa é uma das abordagens metodológicas de pesquisas mais utilizadas na atualidade (Botelho, Cunha \& Macedo, 2011). Diante disso, essa abordagem não necessita de métodos ou técnicas estatísticas. Por este motivo, o pesquisador passa a ser o instrumento-chave (Prodanov \& Freitas, 2013).

A coleta de dados foi realizada a partir de fontes secundárias, por meio de levantamento bibliográfico. Nesse sentido, realizou-se uma busca nas seguintes bases de dados: Biblioteca Virtual de Saúde (BVS), Literatura Latino-Americana e do Caribe em Ciências da Saúde (LILACS), National Library of Medicine National Institu-tes of Health (PubMed), Scientific Eletronic Library Online (Scielo), Science Direct e Ministério da Saúde.

Com relação a busca dos artigos, esta foi realizada nas combinações das línguas inglesa e portuguesa a partir dos seguintes Descritores em Ciência da Saúde (DeCS): anemia falciforme; alterações oculares; retinopatia. Foram utilizadas as combinações a partir dos operadores booleanos retinopathy and sickle cell; retinopatia na anemia falciforme; alterações oculares na anemia falciforme.

Os critérios de inclusão decorreram a partir de artigos que atendem ao gênero analisado parcialmente como retinopatia somente em pacientes com Doença Falciforme e que estejam escritos na língua portuguesa e inglesa, publicados entre os anos de 2010 a 2020. Quanto aos critérios de exclusão, estes se deram a partir dos artigos que trazem alterações 
oculares e retinopatia advindas de outras patologias, não abordando a Doença Falciforme, e que foram publicados fora do recorte temporal estabelecido.

Assim, encontrou-se 40 periódicos nas referidas bases de dados, os quais foram lidos seus títulos e resumos, e os que abordaram o tema pesquisado foram lidos em sua totalidade. Após isso, foram selecionados 13 artigos que abrangiam o estudo em análise, e aqueles que não se enquadraram no foco da pesquisa foram automaticamente descartados. Logo após a seleção dos artigos, realizou-se a leitura flutuante e o fichamento das partes mais importantes dos periódicos, e em seguida os trechos destacados foram colocados em fichas manuais. Posteriormente, os trechos fichados foram passados para um quadro virtual, montado a partir de editor de texto. Por fim, os dados encontrados foram separados e subdivididos em três categorias e organizados em uma tabela criada em ferramenta digital, para então serem analisados e abordados nos resultados e discussão.

De acordo com Câmara (2013), a análise de conteúdo de dados sob a perspectiva qualitativa proporciona uma capacidade produtiva a partir de uma coleta exploratória, o que permite uma categorização e esquematização das informações obtidas, facilitando assim, o embasamento científico relacionado diretamente com o referencial teórico. Dessa forma, de modo geral, esse método permite a flexibilidade das unidades de análise da temática, podendo variar desde palavras ou expressões, ou até mesmo de parágrafos e partes dos textos.

Logo, nessa perspectiva, os artigos selecionados foram lidos em sua totalidade, adotando a técnica de Bardin (2011), a qual tem como principal intuito fazer uma análise crítica do conteúdo estudado, através da compreensão, utilização e aplicação dele. Para tanto, é necessário utilizar as três fases básicas: pré-análise; exploração do material; tratamento dos resultados: inferência e interpretação.

\section{Resultados e Discussão}

Após a análise e seleção, os artigos foram separados em três categorias: prevalência da retinopatia falciforme; classificação da retinopatia de acordo com o grau de acometimento; diferenciação da retinopatia nos subtipos da doença falciforme.

\subsection{Prevalência da Retinopatia Falciforme}

Dos 13 artigos analisados, 12 autores descrevem a Retinopatia Falciforme como uma doença com início silencioso e assintomático, que pode evoluir gradativamente para 
retinopatia falciforme não proliferativa ou retinopatia falciforme proliferativa, sendo essa última de maior prevalência e caracterizada como uma das principais complicações oftalmológicas mais graves da Doença Falciforme, sendo capaz de provocar danos irreversíveis na acuidade visual do paciente, tal como a cegueira total.

A priori, apesar da doença falciforme ser considerada uma patologia de ação sistêmica no organismo humano, os olhos fazem parte dos órgãos alvos atingidos. Nessa perspectiva, Myint, Sahoo, Thein \& Moe (2015); Lim \& Cao (2018) relatam a existência de episódios de estresse constante sofrido na região ocular, seja de forma aguda ou crônica, os quais lesionam principalmente a área da retina, o que pode proporcionar um agravo no quadro clínico do paciente quando há a presença de afinamento temporal.

Diante disso, os episódios citados acima decorrentes de retinopatia proliferativa, são os principais fatores que corroboram para piora gradual da deficiência visual (Dembelé, Toure, Sarro, Guindo, Fané, Offredo \& Diallo, 2017). Sob o mesmo ponto de vista, Bonanomi \& Lavezzo (2013); Melo (2014); Ribeiro, Jucâ, Alves, Ferreira, Barbosa \& Ribeiro (2017) afirmam que a taxa de prevalência da Retinopatia em indivíduos afetados com Doença Falciforme é em torno de 10 a 20\% no geral. Das pessoas acometidas, aproximadamente de $42 \%$, podem apresentar complicações com manifestação de perda visual decorrente da retinopatia de forma branda a partir da segunda década de vida que se agrava com o aumento da idade dos pacientes (Melo, 2014; Ribeiro et al., 2017).

Contudo, na atualidade ocorre uma prevalência de $33 \%$ no acometimento da retinopatia em pacientes falciformes na fase adulta (Rezende, Campos, Vieira, Souza, Belisário \& Silva, 2018). Sendo assim, observa-se que ao longo dos anos, a manifestação inicial da retinopatia nos pacientes que possuem algum tipo de células falciformes, vinha sendo associada apenas na fase de vida adulta. Fato eventualmente explicado, quando se analisa as pesquisas científicas e percebe que a maioria delas se concentra nesse respectivo público alvo. Provavelmente, associado pela causa circunstancial imposta pela patologia, devido à mesma possuir uma sintomatologia tardia.

Entretanto, Pahl, Green, Bhatia, Chang, Licursi, Briamonte, Smilow \& Chen (2017) relatam que a retinopatia falciforme proliferativa possui uma prevalência no público pediátrico de até $40 \%$, podendo ter uma variação nessa taxa, além de ocorrer uma subnotificação devido à falta de protocolos para diagnósticos realizados por imagens, bem como ambiguidade na classificação da retinopatia por causa de seus vários subtipos. No estudo apresentado pelo mesmo, com 16 adolescentes, foi possível observar que todos apresentaram retinopatia em ao menos um dos olhos. 
Research, Society and Development, v. 9, n. 10, e2839108602, 2020

(CC BY 4.0) | ISSN 2525-3409 | DOI: http://dx.doi.org/10.33448/rsd-v9i10.8602

De acordo Roseberg \& Hutcheson (2010) existe uma prevalência entre 16\% a 96\% de Retinopatia Falciforme nas crianças que contém qualquer subtipo da doença falciforme. Nesse mesmo seguimento, um estudo realizado por Rezende et al., (2018) com 59 crianças que realizaram o exame de fundoscopia, foi constatado que 12 delas já tinham os primeiros indícios de retinopatia, com idade média de 9,5 anos de vida. Dessa forma, atingindo uma taxa de acometimento de $20,3 \%$ na população pediátrica estudada, bem similar das porcentagens encontradas por pesquisas americanas de $16,4 \%$ a $23 \%$.

Por outro lado, Alryalat, Nawaiseh, Aladwan, Roto, Alessa \& Al-omar (2020) afirmam que, em pacientes idosos há uma periodicidade maior de complicações associado a forte presença de sintomatologia da doença, mesmo que eles tenham acuidade visual preservada, chegando próximo da normalidade.

Logo, fica evidente que a retinopatia falciforme pode se manifestar desde a primeira década de vida, evidenciando que a retinopatia pediátrica é subestimada, sendo mais constante do que se imaginava. Sendo assim, percebe-se a extrema necessidade de protocolos de diagnósticos e rastreamento da doença desde cedo, para pacientes com grande risco de desenvolvimento da patologia, mesmo que assintomáticos.

\subsection{Classificação da Retinopatia de Acordo com o Grau de Acometimento}

A retinopatia não proliferativa é caracterizada como a presença de alguns eventos oculares, tais como: hemorragias intra-retinianas; tortuosidade vascular; presença de manchas em tons mais claros, denominadas salmon patch; hiperpigmentações originadas a partir de hemorragias secundárias, intitulada lesões de black suburst; além da presença de maculopatia, a qual pode vir a ocorrer devido a alterações nos capilares perifoveais (Cury, Boa-Sorte, Lyra, Zannete, Lima, Castro \& Gonçalves, 2010).

Ainda que a retinopatia proliferativa tenha, praticamente, a mesma origem da não proliferativa, seu percurso diferencia. Para tanto, Ribeiro et al., (2017) abordam a diferenciação da mesma a partir da classificação feita por Goldberg em 1971, o qual o classificou em cinco estágios a partir do comprometimento retiniano: I, oclusão arteriolar periférica, com presença de hipóxia na retina; II, anastomoses arteriovenosas periféricas, caracterizado pelo surgimento de novos vasos, os quais sofrem dilatação, na tentativa de juntar-se a retina vascular e avascular; III, proliferação neovasculares e fibrosas, os neovasos tendem a aderir o vítreo, além de sofrer auto infartos por possuir fluxos incomuns; IV, 
(CC BY 4.0) | ISSN 2525-3409 | DOI: http://dx.doi.org/10.33448/rsd-v9i10.8602

hemorragia vítrea, originada pelo extravasamento dos neovasos; $\mathrm{V}$, descolamento de retina e perda da visão, ocasionados pela repetição das hemorragias vítreas.

Com isso, após a análise dos artigos foi possível verificar que a classificação realizada por Goldberg continua sendo eficaz e utilizada diariamente pelos especialistas até os dias atuais no diagnóstico de retinopatia em pacientes falcêmicos. Ou seja, tal classificação garante um suporte para escolha da melhor conduta de tratamento da retinopatia, além de colaborar diretamente em um diagnóstico correto e preciso.

Tendo em vista a diferença entre a retinopatia proliferativa e não proliferativa, vários autores buscam diferenciar o tipo de incidência dessas retinopatias nos diferentes subtipos de doença falciforme. Sendo assim, Lim \& Cao (2018) abordam que as pessoas falcêmicas do tipo SS apresentam, mesmo que em menor frequência, complicações retinianas do tipo não proliferativa. No entanto, os pacientes SC costumam apresentar, na maior parte das vezes, a retinopatia de caráter proliferativo, em especial os estágios IV e V.

Assim sendo, Oliveira, Carvalho, Nascimento, Villas Bôas, Castro \& Gonçalves (2014) descrevem que através de estudos realizados puderam perceber que, a partir da visão microscópica, ambos os grupos SS e SC apresentavam retinopatia não proliferativa, tais como: lesões de black sunburst e tortuosidade vascular (representados na Figura 1), sendo a primeira alteração mais comum no grupo SC e a última mais frequente no tipo SS, respectivamente. Além disso, as lesões de salmon patch puderam ser observadas em ambos subtipos da doença falciforme, sendo mais recorrente no grupo SC. 
(CC BY 4.0) | ISSN 2525-3409 | DOI: http://dx.doi.org/10.33448/rsd-v9i10.8602

Figura 1. Retinopatia não proliferativa na doença falciforme: (A) Tortuosidade vascular em olho de paciente falciforme SS; (B) Lesão de Black Sunburst em olho de paciente falciforme SC.
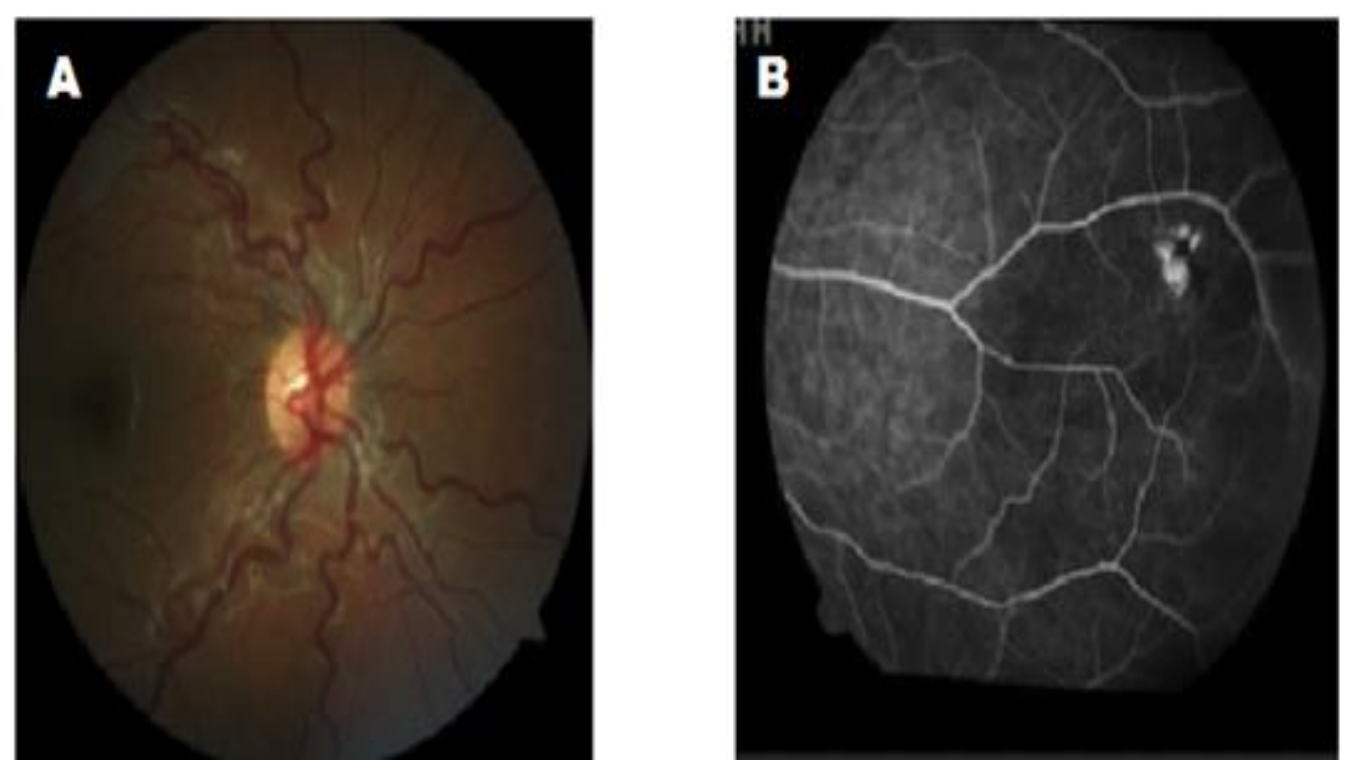

$\mathrm{F}$

Fonte: Oliveira et al., (2014).

A tortuosidade vascular e a lesão de black sunburst são as principais alterações retinianas relatadas na literatura. Dessa maneira, buscando comprovar se essa afirmação condizia com a realidade, Alryalat et al., (2020) realizaram um estudo com 1904 pacientes com Doença Falciforme. Após avaliação da amostra constataram que o que diz na literatura é verídico. Relataram que 443 pacientes apresentavam a lesão de sunburst, sendo 221 (23,8\%) de forma bilateral, e $222(24,0 \%)$ unilateral. Além disso, 341 pacientes $(35,8 \%)$ possuíam tortuosidade vascular bilateral e $18(1,9 \%)$ unilateral.

Em relação a retinopatia falciforme de caráter proliferativo, foi possível analisar que há uma predominância da mesma no subtipo SC, entretanto, o grupo SS também é acometido. Dessa forma, David et al., (2011) abordam que falcêmicos SC são os mais afetados pela retinopatia proliferativa. Além disso, Alryalat et al., (2020), também utilizam dessa afirmação, reiterando que a oclusão arteriolar periférica é o grau mais insidioso neste grupo.

\subsection{Diferenciação da Retinopatia nos Subtipos da Doença Falciforme}

Nos 13 artigos utilizados para a análise de dados, todos os autores trouxeram a diferenciação da retinopatia nos subtipos da Doença Falciforme, onde a retinopatia, em 
especial a proliferativa, está mais presente nas pessoas com o subtipo SC, quando comparados com subtipo SS e S-Tal. Esta frequência de acometimento no grupo SC está relacionada à viscosidade sanguínea, pois este grupo possui o sangue mais viscoso, consequentemente, uma maior porcentagem de hemácias circulantes nos vasos.

Nessa perspectiva, David et al., (2011) aborda que o baixo acometimento da retinopatia proliferativa no subtipo SS está diretamente ligado a presença da anemia hemolítica, havendo uma diminuição nos valores do hematócrito. Esta baixa no hematócrito contribui para uma menor viscosidade do sangue, evitando grande parte dos fenômenos vasooclusivos nas microcirculações.

Entretanto, o fato de se ter uma elevada incidência da retinopatia no grupo SC não anula a presença deste fenômeno nos demais subtipos. Sendo assim, Lim \& Cao (2018) abordaram em seus estudos que, há um maior desgaste da retina nas pessoas SS, diferente dos outros grupos. Esta deterioração do tecido da retina está associada a elevadas crises vasooclusivas deste grupo, resultando em uma menor perfusão de oxigênio no tecido retiniano, corroborando para uma elevada destruição dele.

Quando analisados os artigos na perspectiva de incidência da retinopatia relacionados à idade, alguns dos autores abordam que o surgimento desta patologia nos falcêmicos ocorre, em média, a partir dos 15 anos de vida, sendo notório que há um aumento no número de casos, podendo ocorrer uma piora do prognóstico com o avanço da idade.

Contudo, Bonanomi \& Lavezzo (2013) relatam que na vida adulta há uma maior frequência de surgimento da retinopatia nas pessoas com Doença Falciforme. No entanto, o grupo SC possui grandes chances de incidência na faixa etária de 15 e 24 anos nos homens e 25 a 39 anos nas mulheres. Já o tipo SS, a ocorrência passa a ser entre 25-39 anos para ambos os sexos. Entretanto, Cury et al., (2010) aborda que o grupo SS costuma desenvolver alterações retinianas entre os 20 a 39 anos, e o SC entre os 40 e 50 anos.

Em contrapartida aos dados citados acima, Oliveira et al., (2014) realizou um estudo com crianças e adolescentes com Doença Falciforme no Nordeste do Brasil, o qual constata que a ocorrência de alterações oculares e retinianas no tipo SS surgem na faixa etária de 0 a 9 anos de idade. Já no grupo SC, essas modificações costumam ser mais frequentes dos 10 aos 18 anos de vida. 


\section{Considerações Finais}

A Doença Falciforme é classificada como um conjunto de hemoglobinopatias de caráter genético e hereditário. Após a sua descoberta, ela foi associada e caracterizada como uma doença de pessoas negras, devido a sua alta prevalência neste grupo. No entanto, essa caracterização foi se modificando após a miscigenação genética e racial, passando a ser uma patologia que afeta também, pessoas brancas e pardas.

Por ser uma patologia que modifica o formato das hemácias, tornando-as falcizadas, e impedindo-as de exercer o transporte de oxigênio de forma adequada, a mesma pode ser subdividida em HbSS, HbSC e HbS-Tal. As pessoas que possuem esta doença acabam vir a sofrer de crises álgicas, que são oriundas do processo de vaso-oclusão. Além de proporcionar episódios agudos de dor, a vaso-oclusão das pequenas e grandes circulações pode proporcionar o surgimento de outras patologias, sendo a retinopatia falciforme uma delas.

A retinopatia falciforme, por sua vez, pode vir a se apresentar de duas formas: retinopatia falciforme proliferativa e não proliferativa, sendo a primeira a forma mais grave da doença e a última a forma mais leve, respectivamente. Esta doença ataca a retina, comprometendo a acuidade visual dos pacientes que por ela são acometidos, podendo levá-los ao estado de cegueira parcial ou total.

Desse modo, o presente estudo foi realizado com o objetivo de identificar quais fatores desencadeiam a retinopatia em pessoas com Doença Falciforme. A partir da análise do material escolhido, foi possível verificar que a retinopatia falciforme está presente, em torno de 10 a $20 \%$ da população falcêmica. Estas pessoas, em especial as do tipo SC, possuem um maior acometimento da retinopatia, sendo mais recorrente a de caráter proliferativo. No entanto, os indivíduos SS também são acometidos pela retinopatia em seus dois estados: proliferativo e não proliferativo, sendo a última mais frequente.

Sendo assim, este estudo aborda um tema rico e amplo, considerado de grande relevância para comunidade científica e saúde pública do país, visto que, a retinopatia falciforme está cada vez mais presente no cotidiano dos pacientes com doença falciforme, o que evidencia a necessidade de um atendimento multiprofissional integralizado de maneira holística, a fim de evitar agravamento e complicações futuras da patologia.

Ademais, foi possível observar que os constantes episódios de estresse oxidativo associados aos processos de vaso-oclusões das microcirculações na região orbital são os principais fatores que contribuem para o surgimento da retinopatia nos pacientes com Doença Falciforme. Dessa forma, evidenciou-se que a presença dos processos citados anteriormente é 
responsável por causar danos severos na retina, podendo variar a intensidade da lesão do tecido retiniano e o nível de acometimento de acuidade visual de acordo com a localidade da lesão e o grau de intensidade dela.

Em virtude disso, é possível considerar que os objetivos para realização do estudo, assim como, o problema que norteou a pesquisa, foram atingidos e contemplados. Mas ressaltamos que a perspectiva de entendimento e investigação não foram esgotadas, uma vez que o trabalho apresenta lacunas que podem ser exploradas e respondidas através de uma análise mais profunda sob outros pontos de vista do tema estudado.

Nesse contexto, os estudos aqui apresentados podem contribuir para uma melhor análise, e avaliação contínua das lesões oftalmológicas provocadas pela retinopatia nos pacientes com Doença Falciforme, fatores de risco, prognóstico, terapia preventiva eficaz e prevalência. Como também, colaborar para uma diminuição do desenvolvimento da cegueira, consequentemente melhorando a qualidade de vida desses pacientes.

Portanto, é notório a falta de estudos atuais no Brasil, principalmente no estado da Bahia, que abranja um maior número pacientes que apresentem retinopatia falcêmica, visando estabelecer protocolos clínicos de diagnósticos precoces de acordo com cada faixa etária e subtipo da doença falciforme, HbSS e HbSC, instituindo assim, o melhor método terapêutico oftalmológico de acordo com a progressão e tipo da lesão.

\section{Referências}

Alryalat, S. A., Nawaiseh, M., Aladwan, B., Roto, A., Alessa, Z. \& Al-omar, A. (2020). Ocular Manifestations of Sickle Cell Disease: Signs, Symptoms and Complications. Ophthalmic Epidemiology. 27(4), 259-264. Recuperado de https://doi.org/10.1080/09286586.2020.1723114.

Brasil, Ministério da Saúde (2014). Doença Falciforme: o que se deve saber sobre herança genética. Brasília: Ministério da Saúde. Recuperado de https://bvsms.saude.gov.br/bvs/p ublicacoes/doenca_falciforme_deve_saber_sobre_heranca.pdf.

Bonanomi, M. T. B. C. \& Lavezzo, M. M. (2013). Sickle cell retinopathy: diagnosis and treatment. Arq Bras Oftalmol. 76(5), 320-7. Recuperado de https://doi.org/10.1590/S000427492013000500016. 
Botelho, L. L. R., Cunha, C. C. A. \& Macedo, M. (2011). O Método da Revisão Integrativa nos Estudos Organizacionais. Belo Horizonte: Gestão e Sociedade. 5(11), mai/ago. Recuperado de https://doi.org/10.21171/ges.v5i11.1220.

Câmera, R. H. (2013). Análise de conteúdo: da teoria à prática em pesquisas sociais aplicadas às organizações. Gerais: Revista Interinstitucional de Psicologia, 6(2), jul, 179-191. Recuperado de http://pepsic.bvsalud.org/scielo.php?script=sci_abstract\&pid=S1983$82202013000200003 \& \operatorname{lng}=$ pt\&nrm=iso.

Cury, D., Boa-Sorte, N., Lyra, I. M., Zannete, A. D., Lima H. C., Castro, B. G. \& Gonçalves, M. S. (2010). Ocular lesions in sickle cell disease patients from Bahia, Brazil. Rev Bras Oftalmol; 69(4), 259-63. Recuperado de http://dx.doi.org/10.1590/S003472802010000400010 .

David, R. C., Junior Moraes H. V. \& Rodrigues, M. P. M. (2011). Alterações oculares e eletrorretinográficas na doença falciforme. Arq Bras Oftalmol. 74(3), 190-4. Recuperado de https://doi.org/10.1590/S0004-27492011000300009.

Dembélé, A. K., Toure, B. A., Sarro, Y. S., Guindo, A., Fané, B., Offredo, L. \& Diallo, D. A. (2017). Prévalence et facteurs de risque de la rétinopathie drépanocytaire dans un centre de suivi drépanocytaire d'Afrique subsaharienne. La Revue de Médecine Interne. 38(9), 572-577. Recuperado de http://dx.doi.org/10.1016/j.revmed.2017.01.010.

Lim, J. I. \& Cao, D. (2018). Analysis of Retinal Thinning Using Spectraldomain Optical Coherence Tomography Imaging of Sickle Cell Retinopathy Eyes Compared to Age and Race Matched Control Eyes. Am J Ophthalmol. 192, 229-238, ago. Recuperado de doi: 10.1016/j.ajo.2018.03.013.

Melo, M. B. (2014). An eye on sickle cell retinopathy. Rev bras hematol hemoter. São José do Rio Preto. 36(5), 319-321, set/out. Recuperado de https://doi.org/10.1016/j.bjhh.2014.07.020.

Mendes, K. D. S., Silveira, R. C. C. P. \& Galvão, C. M. (2008). Revisão integrativa: método de pesquisa para a incorporação de evidências na saúde e na enfermagem. Texto \& Contexto 
Enferm, Florianópolis. 17(4), out/dez. Recuperado de https://doi.org/10.1590/S010407072008000400018 .

Myint, K. T., Sahoo, S., Thein, A. W., Moe, S. \& NI, H. (2015). Laser therapy for retinopathy in sickle cell disease. Cochrane Database of Systematic Reviews. 9(10), out. Recuperado de https://doi.org/10.1002/14651858.cd010790.pub2.

Oliveira, D. C., Carvalho, M. O. S., do Nascimento, V. M. L., Villas Bôas, F. S., GalvãoCastro, B. \& Goncalves, M. S. (2014). Sickle cell disease retinopathy: characterization among pediatric and teenage patients from northeastern Brazil. Revista Brasi-leira de Hematologia e Hemoterapia. José do Rio Preto. 36(5), 340-4, set/out. Recuperado de https://doi.org/10.1016/j.bjhh.2014.07.012.

Pahl, D. A., Green, N. S., Bhatia, M., Lee, M. T., Chang, J. S., Licursi, M., Briamonte, C., Smilow, E. \& Chen, A. W. S. (2017). Optical Coherence Tomography Angiography and Ultra-widefield Fluorescein Angiography for Early Detection of Adoles-cent Sickle Retinopathy. Am J Ophthalmol. 183, 91-98. Recuperado de https://doi.org/10.1016/j.ajo.2017.08.010.

Prodanov, C. C., \& Freitas, E. C. (2013). Metodologia do trabalho científico: métodos e técnicas da pesquisa e do trabalho acadêmico. 2. ed. Novo Hamburgo: Feevale. Recuperado de http://www.feevale.br/Comum/midias/8807f05a-14d0-4d5b-b1ad-1538f3aef538/Ebook\%20Metodologia\%20do\%20Trabalho\%20Cientifico.pdf.

Rezende, P. V., M. V., Campos, G. F., Vieira, L. L. M., Souza, Belisário, A. R., Silva, C. M. \& Viana, M. B. (2018) Clinical and hematological profile in a newborn cohort with hemoglobin SC. Sociedade Brasileira de Pediatria. 94(6), 666-672, nov/dez. Recuperado de https://doi.org/10.1016/j.jped.2017.09.010.

Ribeiro, M. V. M. R., Jucâ, J. V. O., Alves, A. L. C. S., Ferreira, C. V. O., Barbosa, F. T. \& Ribeiro, E. A. N. (2017). Sickle cell retinopathy: A literature review. Rev Assoc Med Bras. 63(12), 1100-1103. Recuperado de http://dx.doi.org/10.1590/1806-9282.63.12.1100. 
Rosenberg, J. B. \& Hutcheson, K. A. (2011). Pediatric sickle cell retinopathy: Correlation with clinical factors. Journal of AAPOS. 15(1), 49-53, fev. Recuperado de https://doi.org/10.1016/j.jaapos.2010.11.014.

Souza, M. T., Silva, M. D. \& Carvalho, R. (2010). Revisão integrativa: o que é e como fazer Integrative review: what is it? How to do it?. Einstein. São Paulo. 8(1), 102-6, jan/mar. Recuperado de https://doi.org/10.1590/s1679-45082010rw1134.

Porcentagem de contribuição de cada autor no manuscrito
Arthur Freitas do Nascimento - 40\%
Lorrana Figueirêdo Pereira $-40 \%$
Márcio Cerqueira de Almeida - 10\%
José Eduardo Teles de Andrade - 3\%
Claudilson Souza Dos Santos - 3\%
Morganna Thinesca Almeida Silva - 2\%
Edilson da Silva Pereira Filho - 2\% 